\title{
ENHANCEMENT OF CONCRETE PIPES THROUGH REINFORCEMENT WITH DISCRETE FIBERS
}

\author{
Parviz Soroushian ${ }^{1}$ and Shervin Jahangirnejad ${ }^{2}$
}

1. President, Metna Co., 3927 Dobie Road, Okemos, MI 48864, USA; metnaco@gmail.com

2. Associate, Shannin and Wilson, Inc., 3990 Collins Way, Suite100, Lake Oswego, OR 97035, USA; SHJ@shanwil.com

\begin{abstract}
An industrial-scale production and experimental investigation was conducted in order to evaluate the constructability and structural performance of different concrete pipes incorporating discrete synthetic fibers. The results indicated that synthetic fibers enable design of plain concrete pipes with a desired balance of strength and ductility. Analytical models were developed for predicting the load-carrying capacity of concrete pipes without steel reinforcement that are reinforced with discrete fibers.
\end{abstract}

\section{KEYWORDS}

Concrete pipe, Fiber reinforcement, Strength, Ductility, Damage resistance, Experimental evaluation, Analytical modeling

\section{INTRODUCTION}

Concrete pipes, manholes, pump stations, wet wells, etc. represent close to half of the investment in the infrastructure for the 20,000 sewer systems in the United States. Concrete has reached its position of prevalence in the sewer infrastructure through satisfactory performance over long periods of time [1]. The concrete-based sewer infrastructure offers a desired balance of durability, structural efficiency, and initial as well as life-cycle economy. In recent years, however, incidents of severe damage to the concrete-based sanitary sewer infrastructure have increased significantly [2]. There is a need to improve the damage resistance and service life of concrete pipes [3]. Synthetic fiber reinforcement of concrete is used in this investigation to enhance the structural performance of plain concrete pipes.

\section{EXPERIMENTAL MATERIALS AND METHODS}

Pipes were fabricated in the industrial facility of the Northern Concrete Pipe Inc. (Charlotte, MI, USA) using different concrete materials. This facility uses the dry-cast method of concrete pipe production. The effects of fiber reinforcement on the structural performance of concrete pipes were investigated. The fiber volume fraction and geometry were the key variables of the experimental program. Synthetic fibers with different lengths and diameters were used in concrete pipes as full replacement for steel reinforcement. 


\section{Materials}

Fiber geometry and volume fraction were the primary variables in formulation of materials. PVA (Polyvinyl Alcohol) fibers were used in this investigation; three fiber geometries were considered (see Tab. 1). The fiber volume fraction ranged from 0 to $2 \%$.

Tab. 1 - Pipe fiber reinforcement conditions (no continuous steel reinforcement)

\begin{tabular}{|l|c|c|c|c|c|}
\hline \multirow{2}{*}{ Pipe } & \multirow{2}{*}{ Fiber Vol.\% } & \multicolumn{4}{|c|}{ Fiber Properties } \\
\cline { 3 - 6 } & & Type & Length, $\mathrm{mm}(\mathrm{in})$ & Diameter, mm (in) & Tensile Strength, MPa (psi) \\
\hline$\# 6$ & $0 \%$ & - & - & - & - \\
\hline$\# 7$ & $0.5 \%$ & I & $6(0.24)$ & $0.001(0.026)$ & $1600(232000)$ \\
\hline$\# 8$ & $0.5 \%$ & II & $12(0.47)$ & $0.1(0.0039)$ & $1100(159500)$ \\
\hline$\# 14$ & $0 \%$ & - & - & - & - \\
\hline$\# 15$ & $2 \%$ & III & $15(0.59)$ & $0.3(0.012)$ & $900(130500)$ \\
\hline
\end{tabular}

\section{Concrete Mix Proportions and Pipe Dimensions}

The base concrete mixture used for industrial-scale production of concrete pipes had an aggregate-to-binder ratio of 5.5, with fine-to-coarse aggregate ratio of 1.5 , and water-to-binder ratio of 0.34. This mix provided adequate stability in fresh state for immediate demolding of the pipe. In mixtures that incorporated finer synthetic fibers, the total aggregate content was reduced by $10 \%$ in order to increase the paste content for enhancing the dispersion and interfacial bonding of fibers.

All pipes were standard class IV, wall C. This type of pipe is characterized by an internal diameter of $686 \mathrm{~mm}$ (27 inches), a wall thickness of $102 \mathrm{~mm}$ (4 inches), and a length of $2.59 \mathrm{~m}$ (8.5 feet) [4].

\section{Test Method}

Three-Edge Bearing Tests were performed on all pipes per ASTM C497. In this test, the pipe is supported on two parallel longitudinal strips, and the load is applied uniformly along the pipe length using an upper bearing strip (Figure 1). The lower and upper bearing strips are extended the full length of the pipe. Under increasing load levels in the tree-edge bearing test, first cracks develop along the pipe length on the top and bottom (crown and invert) interior surfaces of the pipe (Figure 2). Further increase in load generates horizontal side cracks on the outside surface of pipes. The load corresponding to 0.25 $\mathrm{mm}$ ( $0.01 \mathrm{in})$ crack width was determined through monitoring of the width of the first crack formed on the interior surface of the pipe. The peak load as well as the load-deflection behavior of the pipe were also obtained in the three-edge bearing tests. The load-deflection curves reflect upon the ductility and energy absorption capacity of pipes. 


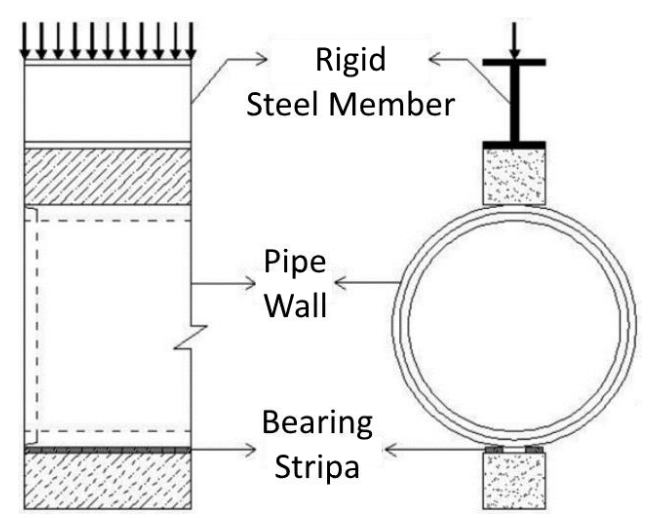

(a) Schematics

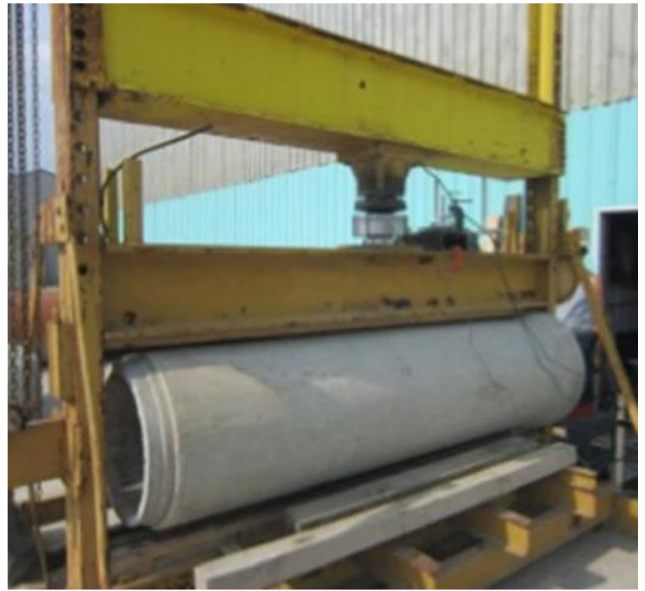

(b) Picture

Fig. 1 - Test setup.

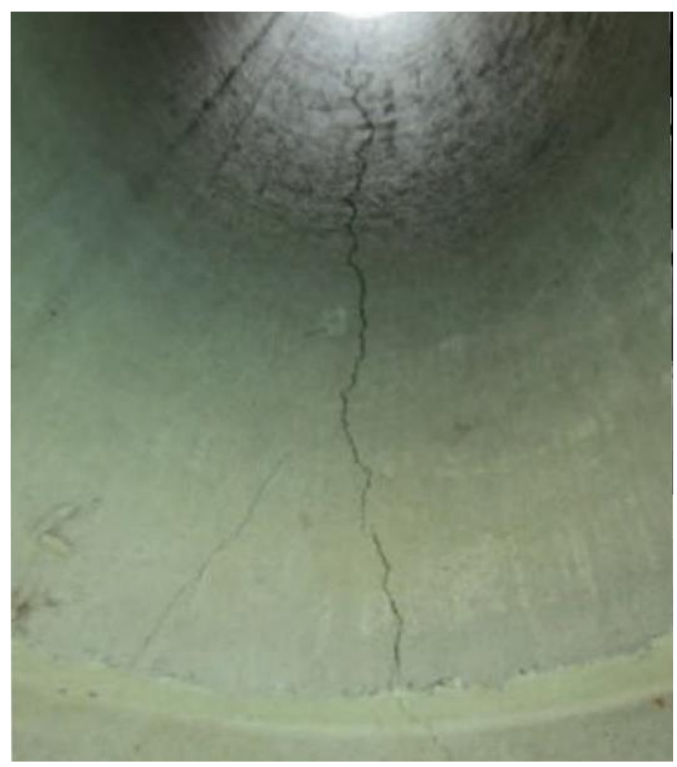

Fig. 2 - The initial bottom crack in pipe subjected to the three-edge bearing test.

\section{TEST RESULTS AND DISCUSSION}

The loads corresponding to $0.25 \mathrm{~mm}(0.01 \mathrm{in})$ crack width as well as the first-crack and peak loads are presented in Table 2. Figure 3 shows the load-deflection responses generated in the threeedge bearing tests of concrete pipes with different fiber reinforcement conditions. It should be noted that the concrete pipe \#15 with $2 \%$ volume fraction of coarse $15 \mathrm{~mm} \times 0.3 \mathrm{~mm}(0.59$ in $\times 0.012$ in) PVA fibers, did not fail in a very brittle (almost explosive) manner in the three-edge bearing test; fiber pullout was prevalent in this case (Figure 4a). Reinforcement with $2 \%$ volume fraction of the coarse $15 \mathrm{~mm} \times 0.3$ 
Article no. 10

THE CIVIL ENGINEERING JOURNAL 1-2021

$\mathrm{mm}$ (0.59 in $\times 0.012 \mathrm{in})$ fiber thus offers the promise to control damage to plain concrete pipes during handling, transportation and installation.

Tab. 2 - Measured values of different load levels in three-edge bearing tests on concrete pipe

\begin{tabular}{|l|c|c|c|}
\hline Pipe & First Crack Load, $k N(\mathrm{lb})$ & Load @ 0.25 mm (0.01 in) Crack, kN (lb) & Peak Load, kN (Ib) \\
\hline$\# 6$ & $211(47,500)$ & $211(47,500)$ & $211(47,500)$ \\
\hline$\# 7$ & $227(51,000)$ & $231(52,000)$ & $231(52,000)$ \\
\hline$\# 8$ & $214(48,000)$ & $223(50,000)$ & $223(50,000)$ \\
\hline$\# 14$ & $206(46,250)$ & $206(46,250)$ & $206(46,250)$ \\
\hline$\# 15$ & $238(53,500)$ & $238(53,500)$ & $238(53,500)$ \\
\hline
\end{tabular}

The three-edge bearing test results for the first series of pipes presented above indicates that:

1. Pipes \#6, \#7 \& \#8 provide a basis to assess the potential of fibers to overcome the brittle mode of failure in plain concrete pipes (without continuous steel reinforcement). Many concrete pipes do not need steel reinforcement for load-bearing capacity. Steel is added to these pipes (with important implications in terms of cost and production effort) mainly to avoid damage to these brittle pipes during transportation and installation. Synthetic fibers could be a cost-effective replacement for steel as far as they ensure ductile failure mode of pipes. In the case of plain concrete pipes, with conventional hydraulic loading systems used for the performance of threeedge bearing tests, the gains in ductility with $0.5 \%$ fiber volume fraction (Pipes \#7 \& \#8) are relatively small (compared with Pipe \#6). This, however, could be a result of the load-controlled nature of the hydraulic loading system. This system, in combination with the test frame, act as a spring within which mechanical energy accumulates as the peak load is approached. Although the fiber reinforced concrete pipes (without steel reinforcement) would have some level of postpeak ductility for adequate resistance to brittle modes of failure during transportation and installation, the energy accumulated within the hydraulic loading system (and test frame) is suddenly released once the peak load is reached, causing sudden failure of pipe irrespective of the post-peak ductility provided by fiber reinforcement of plain concrete pipes. In other words, the brittle mode of failure in fiber reinforced concrete pipes (without steel reinforcement) in threeedge bearing test does not necessarily imply that these pipes are prone to damage during transportation and installation.

2. Coarser fibers $15 \mathrm{~mm} \times 0.3 \mathrm{~mm}(0.59$ in $\times 0.012 \mathrm{in})$ can be more conveniently introduced at relatively high volume fractions $(2 \%)$ into the concrete mixtures used in the dry-cast method of pipe production. Finer fibers with higher specific surface areas require increased paste and plasticizer contents for uniform dispersion in concrete mixtures with adequate workability. Minor balling of fibers during production was observed (Figure 4b), which could be resolved through a slight increase in the paste content of concrete and also by pre-wetting of the hydrophilic PVA fibers. 
3. The coarser PVA fiber exhibited a prevalent tendency towards pullout at cracks while the finer PVA fibers predominantly ruptured at cracks. The frictional pullout of coarser fiber benefits their contribution towards the ductility and energy absorption capacity of concrete pipes, which can be used to prevent brittle failure of plain concrete pipes and thus facilitate production of plain pipes which are resistant to damage during handling, shipment and installation.

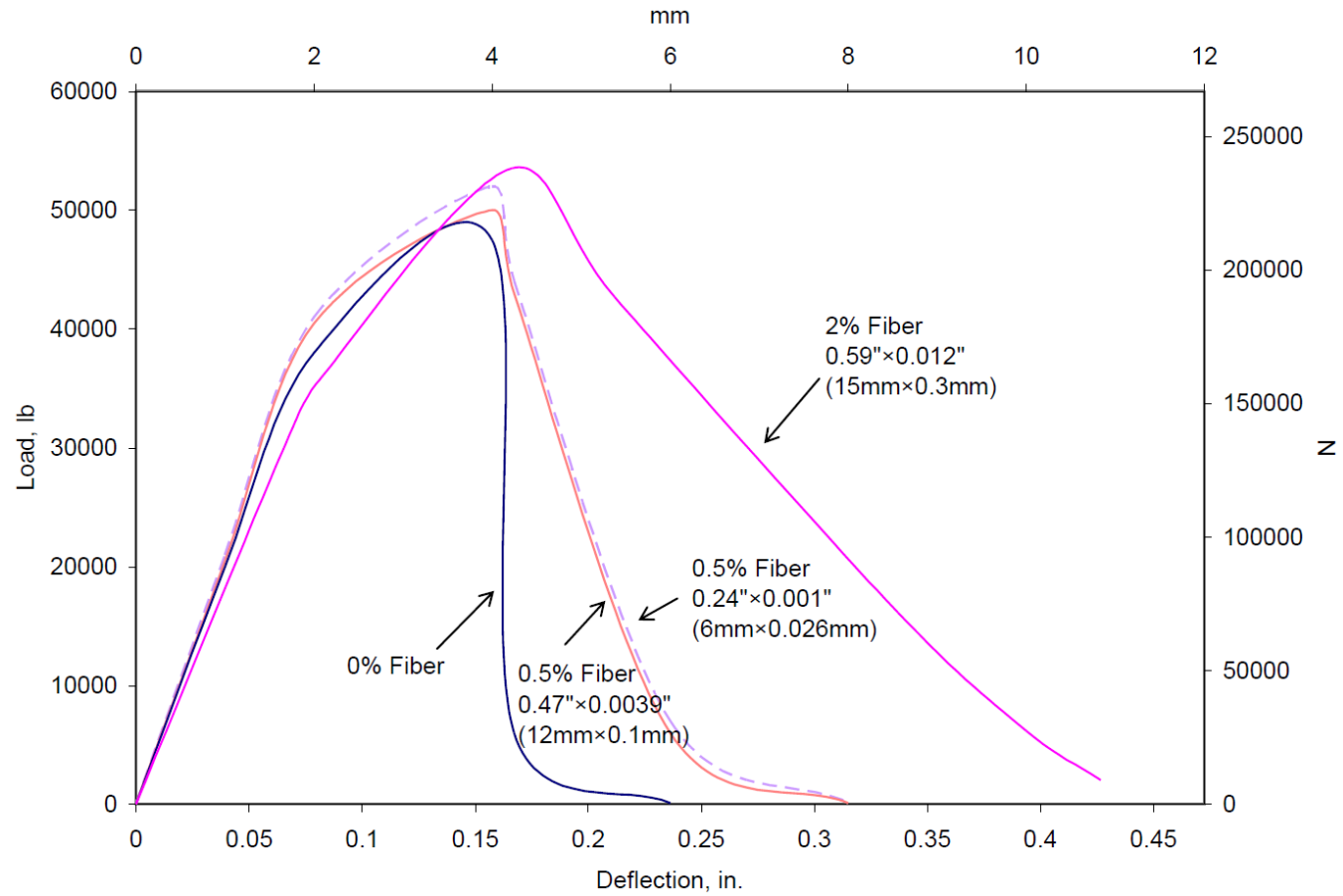

Fig. 3 - Load-deflection curves of concrete pipes with different fiber reinforcement conditions

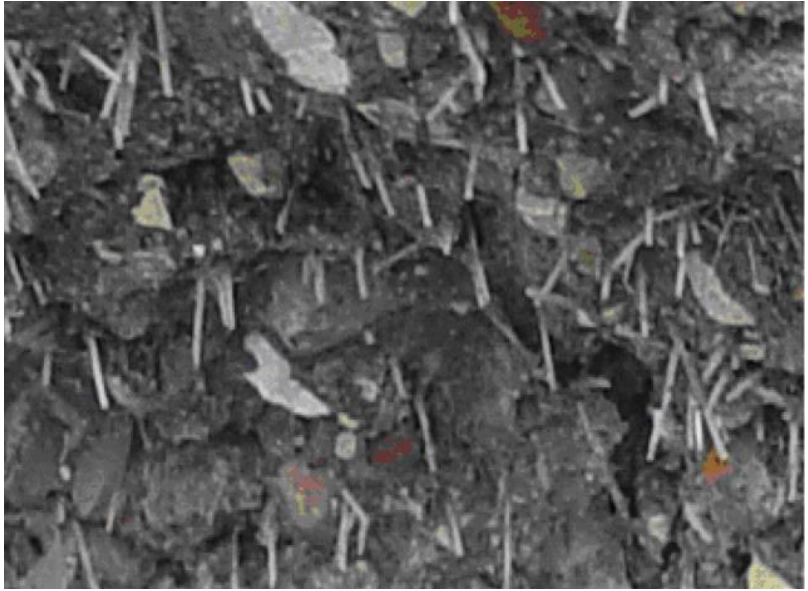

(a) Uniform fiber dispersion

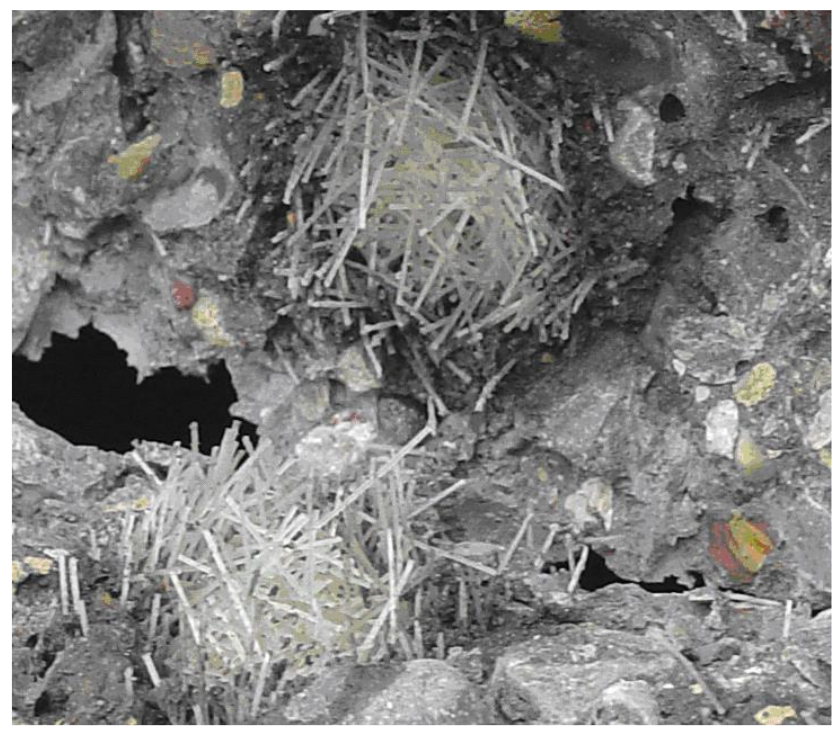

(b) Occasional fiber balling

Fig. 4 - Fiber dispersion conditions 


\section{ANALYTICAL INVESTIGATION}

Pipes are subjected to earth and live loads which generate transverse bending moments in pipe walls. The transverse (circumferential) reinforcement is used in concrete pipes to resist bending moments. Under loads, pipes first develop vertical (crown and invert) cracks starting at interior surfaces, and then horizontal (springline) cracks starting at mid-height on exterior surfaces. Under the effect of bending moments, the pipe wall behaves as a rectangular reinforced concrete section.

Concrete pipes with limited demand on their load-bearing capacity may be unreinforced. Design of concrete pipes is based primarily on their flexural performance under external loads. One load criterion, that is ultimate load in three-edge bearing test, is generally used in design of concrete pipes. The analytical work presented herein seeks to establish a theoretical framework for prediction of the load levels in plain concrete pipes with synthetic fiber reinforcement.

\section{Plain Concrete Pipes}

Ultimate (D-)Load is calculated using the following equation $[5,6]$ :

$$
f_{m r}=0.96 \phi_{m r} \frac{D L_{u t} \times D_{i}\left(D_{i}+h\right)}{144 h^{2}}
$$

where

$D L_{u t}=$ the D-load that cracks the pipe $(\mathrm{lb} / \mathrm{ft} / \mathrm{ft})$

$D_{i}=$ the internal diameter of the pipe (in), $\mathrm{h}$ is the wall thickness (in)

$f_{m r}=$ the modulus of rupture (flexural strength) of concrete (psi)

\section{Modification of Design Equations to Account for the Effects of Synthetic Fibers}

Fiber reinforcement of concrete enhances its flexural load-bearing capacity at different stages of performance. This is due to the crack arrest action, tensile force resistance and frictional pullout of fibers in regions of concrete that experience tensile stresses. The simplified approach adopted here accounted for the contributions of fibers to the flexural strength of concrete.

Fibers in a cementitious matrix exhibit two types of behavior at cracks: pull-out, or rupture. The synthetic (PVA) fibers used in this investigation exhibit a stronger tendency towards rupture (especially for finer diameters and higher aspect ratios). The reason is the hydrophilic nature and strong bonding of PVA fibers to the cementitious matrix. The tendency towards fiber pull-out increases with increasing fiber diameter and decreasing fiber aspect ratio. Various methods have also been employed to promote fiber pull-out for enhancing the toughness and energy absorption capacity. These methods include use of an oiling agent and modifying the matrix to reduce the chemical and frictional bonding to PVA fibers.

\section{Design Equations When Fiber Rupture Dominates}

The fiber concrete tensile stress distribution at flexural failure is assumed to be triangular (linear) based on past experience [7]. Fibers act in tension within the tensile zone of the concrete pipe crosssection. This zone starts at neutral axis, and covers the full area towards the surface with peak tensile stress. Equilibrium of forces yield the expression for flexural strength. 
The above approach together with equilibrium considerations for the flexural stress distribution of Figure 5 yield the nominal flexural strength of fiber reinforced concrete section.

$$
M_{n}=F_{m r}+\left[\frac{\sigma_{t}(h-c)}{2} b\left(\frac{2(h-c)}{3}\right)\right]
$$

where

$\sigma_{t}=$ the tensile stress in fibrous concrete, and is calculated as follows:

$\sigma_{t}=(\mathrm{N}=$ number of fibers per unit area $){ }^{*}(\mathrm{U}=$ ultimate tensile force of a single fiber $)$

$$
\sigma_{t}=\left(\frac{0.5 V_{f}}{\frac{\pi d_{f}^{2}}{4}}\right)\left(\sigma_{f u} \frac{\pi d_{f}^{2}}{4}\right)
$$

Therefore,

$$
\sigma_{t}=0.5 V_{f} \sigma_{f u}
$$

In the above formula, $\mathrm{N}$ is the number of (3D) distributed fibers per unit cross-sectional area.

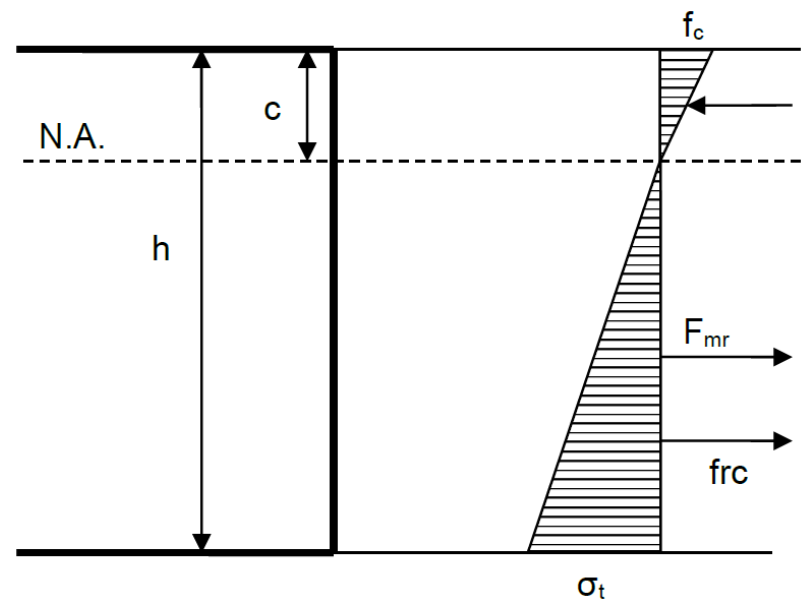

Fig. 5. - Flexural stress distribution at ultimate condition for a non-reinforced fiber concrete section.

\section{Design Equations When Fiber Pull-Out Dominates}

When fiber pull-out dominates, the fiber concrete tensile stress distribution is assumed to be the same as previous case. 


$$
M_{n}=F_{m r}+\left[\frac{\sigma_{t}(h-c)}{2} b\left(\frac{2(h-c)}{3}\right)\right]
$$

The tensile stress in fibrous concrete $\left(\sigma_{t}\right)$ is, in this case, equals to:

$$
\sigma_{t}=N . F
$$

where

$N=$ number of fibers per unit area

$F=$ mean fiber frictional pullout resistance.

For randomly (3D) oriented short fibers,

$$
\mathrm{N}=\left(\frac{0.5 V_{f}}{\frac{\pi d_{f}^{2}}{4}}\right)
$$

When fiber pull-out dominates (over an average length that is one-quarter of fiber length),

$$
\mathrm{F}=\left(\tau_{f} \pi d_{f} \frac{l_{f}}{4}\right)
$$

Therefore,

$$
\sigma_{t}=\left(\frac{0.5 V_{f}}{\frac{\pi d_{f}^{2}}{4}}\right)\left(\tau_{f} \pi d_{f} \frac{l_{f}}{4}\right)
$$

which can be simplified to:

$$
\sigma_{t}=0.5 V_{f} \tau_{f} \frac{l_{f}}{d_{f}}
$$

\section{ANALYTICAL PREDICTIONS VERSUS EXPERIMENTAL RESULTS}

The fiber concrete pipes tested in experimental investigations had the following properties:

$f_{c}=34.5 \mathrm{MPa}(5000 \mathrm{psi}(34.5 \mathrm{MPa})$

$W_{p}=624 \mathrm{~kg} / \mathrm{lin} . \mathrm{m}(420 \mathrm{lb} / \mathrm{lin} . \mathrm{ft})$

$f_{m r} \cong 3.66 \mathrm{MPa}(530 \mathrm{psi})$ 


$$
\begin{aligned}
& h=102 \mathrm{~mm}(4 \mathrm{in}) \\
& D_{i}=686 \mathrm{~mm}(27 \mathrm{in})
\end{aligned}
$$

The fiber properties were presented in Table 1. Figure 6 presents the experimental results and analytical predictions of the ultimate loads for different pipes considered in the experimental program. Analytical predictions were made based on the assumptions of the predominance of either fiber rupture or pullout, as described in the following. In the case of Pipe \#8, with fibers of medium aspect ratio, some fiber pull-out was observed but fiber rupture was still prevalent. For Pipe \#15, which incorporated coarse fibers, fiber pull-out with a bond strength, $T$, of $10 \mathrm{MPa}(1450 \mathrm{psi})$ [8] yielded a satisfactory analytical prediction of experimental results. Fiber rupture was assumed to be prevalent in Pipe \#7 with the smallest fiber diameter and highest fiber aspect ratio. The predicted value of D-load would have been higher, and closer the experimental value, for Pipe 8 (with intermediate fiber diameter and aspect ratio. The reasonable comparison of the predicted and experimental values for Pipes 7 and 15 could have resulted from the prevalence of fiber router and pullout, respectively, in these pipes.

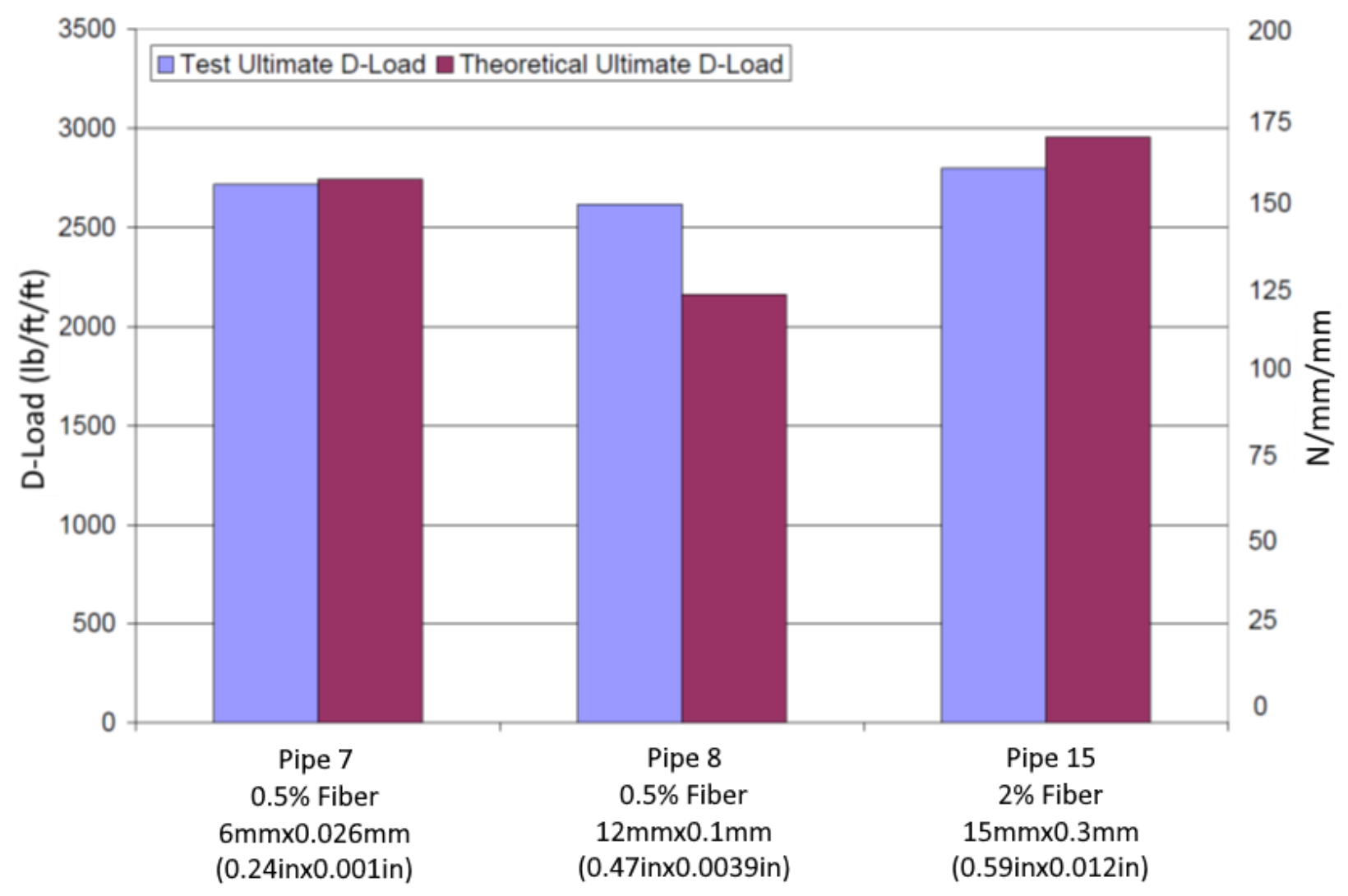

Fig. 6 - Analytical predictions of ultimate loads versus experimental results 


\section{CONCLUSION}

1. Refined concrete mix formulations incorporating synthetic fibers were found to suit industrialscale production of concrete pipes.

2. Synthetic (PVA) fiber reinforcement at about $1 \%$ volume fraction enhances the cracking and peak loads, and the post-peak ductility and damage resistance of concrete pipes.

3. Coarser (larger-diameters) PVA fibers at reasonably high aspect ratios, when compared with finer fibers, can be more conveniently dispersed in the high-performance concrete mixtures used in dry-cast method of concrete pipe production at about $1 \%$ fiber volume fraction, and exhibit a greater tendency towards fiber pull-out (versus rupture) which benefits the ductility and damage resistance of concrete pipes. PVA fibers with $15 \mathrm{~mm}$ (0.59 in) length and $0.3 \mathrm{~mm}$ (0.012 in) diameter perform satisfactorily in dry-cast concrete pipes at about $1 \%$ fiber volume fraction.

4. Concrete pipes with relatively low load-bearing requirements could be designed without steel reinforcement. The potential for damage to concrete pipes during shipment, handling and installation, however, forces the use of steel reinforcement for the purpose of damage control. Reinforcement of plain concrete pipes with coarser PVA fibers can bring about a change from brittle to ductile modes of failure at competitive cost, eliminating the need for conventional steel reinforcement of pipes with relatively low load-bearing requirements. The PVA fiber reinforced concrete pipes offer advantages over conventional steel reinforced pipes in terms of streamlined production, cost, and service life (corrosion resistance).

5. Further work for enhancing the dispersion of synthetic fibers in concrete would enable full realization of the PVA potential for improving the structural performance of concrete pipes.

\section{ACKNOWLEDGEMENTS}

The work reported herein was supported by the United States Environmental Protection Agency. Northern Concrete Pipe, Inc. (Michigan, USA) made its production facilities available for production and experimental evaluation of pipes.

\section{NOTATION}

$D_{i}=$ the internal diameter of the pipe (in), $\mathrm{h}$ is the wall thickness (in)

$D L_{u t}=$ the D-load that cracks the pipe $(\mathrm{lb} / \mathrm{ft} / \mathrm{ft})$

$f_{m r}=$ the modulus of rupture (flexural strength) of concrete (psi)

$F=$ mean fiber frictional pullout resistance.

$\mathrm{N}=$ number of fibers per unit area)

$\sigma_{t}=$ the tensile stress in fibrous concrete, and is calculated as follows:

$U=$ ultimate tensile force of a single fiber 
Article no. 10

\section{CIVIL}

\section{ENGINEERING}

THE CIVIL ENGINEERING JOURNAL 1-2021

\section{REFERENCES}

[1] Alexander, M.G. and C. Fourie, 2011. Performance of swere pipe concrete mixtures with Portland and calcium auminate cements subject to mineral and biogenic acid attack. Materials and Structures, vol 44, no 313330.

[2] Ling, A.L., et al., 2015. High-resolution microbial community succession of microbially induced concrete corrosion in working sanitary manholes. PloS one, vol 10, no 3: p. e0116400.

[3] O'Connell, M., C. McNally and M.G. Richardson, 2010. Biochemical attack on concrete in wastewater applications: a state of the art review. Cement and Concrete Composites, vol 32, no 7: p. 479-485.

[4] American Society for Testing and Matrials, 1999. Standard Specification for Reinforced Concrete Culvert, Storm Drain, and Sewer Pipe, American Society for Testing and Materials.

[5] American Concrete Pipe Association, Concrete pipe technology handbook. Irving, TX, 1993.

[6] Watkins, R.K. and L.R. Anderson, 1999. Structural mechanics of buried pipes, CRC press.

[7] Herrmann, H. and J. Schnell, 2019. Short Fiber Reinforced Cementitious Composites and Ceramics, Springer International Publishing.

[8] Hong, L., Y.D. Chen, T.D. Li, P. Gao and L.Z. Sun, 2020. Microstructure and bonding behavior of fiber -mortar interface in fiber-reinforced concrete, Construction and Building Materials, vol 232: p. 117235. 